\title{
Thermal Stability and Combustion Behaviors of Poly(oxybutylene)amides
}

\author{
Jiang-Jen LIN, ${ }^{\dagger}$ Jeng-Jaw Wu, Shi-Min SHAU, and Yung-Sheng Ho* \\ Department of Chemical Engineering, National Chung-Hsing University, Taichung 402, Taiwan \\ ${ }^{*}$ Refining and Manufacturing Research Center, Chinese Petroleum Corp., Chia-Yi 600, Taiwan
}

(Received October 15, 2001; Accepted December 15, 2001)

\begin{abstract}
Polymerization of 1,2-epoxybutane (BO) with various amides led to a family of gasoline detergents useful for preventing automobile engine valve deposits. Effective compounds are amphiphilic copolymers consisting of a hydrophobic polyoxybutylene backbone and hydrophilic amide functionalities. The engine performances of these polymer additives were correlated with their thermal stability and the combustion behaviors at high temperature. Investigated by using a thermal gravimetric analysis (TGA), we found the thermal stability to have the following trend according to the backbone structures of oxyethylene $>$ oxybutylene $>$ oxypropylene. Furthermore, the presence of amide or multiple amide functionalities in the structures greatly enhanced the backbone stability up to $100^{\circ} \mathrm{C}$ in air and $36^{\circ} \mathrm{C}$ in nitrogen by comparing $50 \mathrm{wt} \%$ decomposition temperatures of the TGA data. The amides are considered as built-in antioxidants for free-radical scavenging and backbone stabilizers.
\end{abstract}

\section{KEY WORDS Gasoline Additive / Detergents / Poly(oxybutylene)amide / Combustion /}

Adding specialty polymers or oligomers into gasoline to enhance engine performance is an important research subjects with respect to preventing deposits in engines, controlling octane requirement increases, improving gasoline economics and minimizing emission pollution. ${ }^{1-5}$ Particularly, the uses of polymeric surfactants as fuel additives for preventing the deposit of intake valves and combustion chamber, and consequently reducing octane requirement of automobile engines and exhaust emission may have great impacts on the fuel economics and environment. Structurally, these specialty additives are generally oil-soluble and high molecular weight of amines such as polyisobutylene amines, ${ }^{6}$ Mannich amines ${ }^{7}$ and polyetheramines, ${ }^{8-11}$ which are added into gasoline at approximately hundred ppm level of concentration. Among these additives, polyetheramines are advantageous over polyalkylene amines due to their low char residues or clean burning at high temperature. ${ }^{12}$ Recently discovered poly(oxyalkylene)amide additives have been claimed to have positive effects on combustion and octane requirement, besides the detergent performance. ${ }^{13-18}$ For the syntheses, the poly(oxyalkylene) backbones are commonly constructed by the ring opening polymerization with 1,2-epoxybutane to obtain more oil-soluble additives, rather than using propylene oxide or ethylene oxide. ${ }^{19}$ The hydrophobic nature of poly(oxybutylene) backbone in combination with the hydrophilic amide groups constituted the amphiphilic surfactants with excellent engine performance. Among various performance aspects, the class of poly(oxybutylene)amides in very low concentration can particularly affect the engine requirement for gasoline octane number. Although there are a great deal of patent reports claiming the effectiveness of these compounds, the structural aspects and chemical nature in relating to engine performance are seldom revealed. ${ }^{13,20}$ This may be due to the lacking of knowledge on the structure/performance relationship, that is, their thermal degradation pattern or the combustion mechanism. Therefore, the understanding of thermal decomposition and engine performance relationship in the molecular level is an important research issue.

In this paper, we study the fundamental factors influencing thermal and thermooxidative stability of these poly(oxyalkylene)amides on the basis of TGA measurements. The relative thermal stability of different poly(oxybutylene)amide derivatives are correlated to the presence of amide groups in the chemical structure. Hydrolyzed amides to the corresponding amines are compared. Engine results are included to correlate with the simulated thermal stability measurement by TGA.

\section{EXPERIMENTAL}

\section{Materials}

The starting materials of poly(oxyalkylene)amines, poly(propylene glycol)bis(2-aminopropyl ether) at average $M_{\mathrm{w}}$ of 230 (Jeffamine ${ }^{\circledR} \mathrm{D} 230$, abbrev. POP230), triethyleneglycoldiamine $\left(M_{\mathrm{w}}=148\right.$, abbrev. ED148) and trimethyol propane initiated poly(pro-

${ }^{\dagger}$ To whom correspondence should be addressed (Tel: +886-4-2285-2591, Fax: +886-4-2287-1787, E-mail: jjlin@dragon.nchu.edu.tw). 


$$
\mathrm{CH}_{3} \mathrm{CH}_{2} \mathrm{CH}_{2} \mathrm{CH}_{2}\left(\underset{\mathrm{R}}{\mathrm{O}} \mathrm{OHCH}_{2}\right)_{n} \mathrm{OH}
$$

BuBO1600: $\mathrm{R}=\mathrm{CH}_{2} \mathrm{CH}_{3} 1600 \mathrm{M}$ BuEO2000 : R = H $2000 M_{w}$

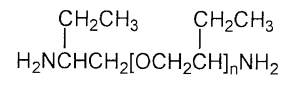

poly(oxybutylene)diamine $2000 M_{w}$ (POB2000)

$$
\stackrel{\mathrm{CH}_{3}}{\mathrm{CH}_{2} \mathrm{CH}_{3}}
$$

poly(oxypropylene)diamine (POP230 : $230 M_{\mathrm{w}}$ ) (POP2000 : $2000 M_{\mathrm{w}}$ )

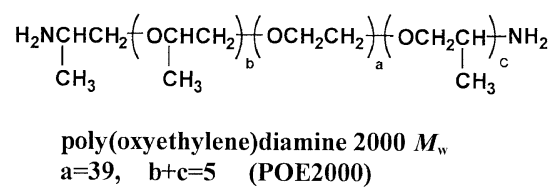

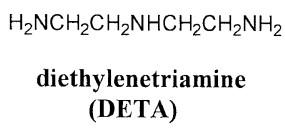

$$
\begin{aligned}
& \mathrm{H}\left(\underset{\mathrm{R}}{\mathrm{O}} \mathrm{OCH}_{2}\right)_{n}-\mathrm{OH} \\
& \text { PEG2000 : R }=\mathbf{H} \\
& \text { PPG2000 : R }=\mathbf{C H}_{3}
\end{aligned}
$$

$\mathrm{H}_{2} \mathrm{NCH}_{2} \mathrm{CH}_{2} \mathrm{OCH}_{2} \mathrm{CH}_{2} \mathrm{OCH}_{2} \mathrm{CH}_{2} \mathrm{NH}_{2}$

triethyleneglycoldiamine (ED148)

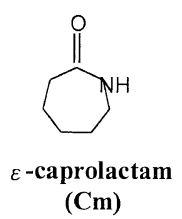

Cm)

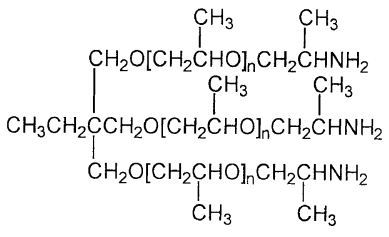

poly(oxypropylene)triamine $400 M_{\mathrm{w}}$ (T400)

Figure 1. Chemical structures of starting materials.

pylene glycol)-tri(2-aminopropyl ether) at $M_{\mathrm{w}}$ of 400 (Jeffamine ${ }^{\circledR}$ T403, abbrev. T400) were purchased from Huntsman Chemical Co. Diethylenetriamine (DETA) and $\varepsilon$-caprolactam $(\mathrm{Cm})$ were purchased from Aldrich Chemical Co. A family of poly(oxybutylene)-, poly(oxypropylene)- and poly(oxyethylene)-backboned diamines of $2000 M_{\mathrm{w}}$, abbreviated as POB2000, POP2000, and POE2000, respectively, were obtained from Aldrich Chemical Co. or Huntsman Chemical Co. Poly(ethylene glycol) (PEG2000) and poly(propylene glycol) (PPG2000) and other analogs were purchased from Aldrich Chemical Co. Structures of these starting materials are illustrated in Figure 1.

\section{Preparation of Amide Initiators}

The preparation of a series of oligo(oxyalkylene)and alkylene-amide and their alkoxylates were carried out according to the conditions reported previously. ${ }^{20}$ The exemplified experimental procedures for preparing amide initiator are described: A mixture of poly(propylene glycol)bis(2-aminopropyl ether) at average $M_{\mathrm{w}}$ of $230(\mathrm{D} 230,59.0 \mathrm{~g}, 0.26 \mathrm{~mol})$ and ethyl acetate $(91.0 \mathrm{~g}, 1.04 \mathrm{~mol})$ was added into an $1 \mathrm{~L}$ autoclave. The autoclave was sealed and purged of air by pressurizing and depressurizing with nitrogen at 500 psi several times. With stirring and under initial nitrogen pressure of $200 \mathrm{psi}$, the mixture was heated slowly to $180^{\circ} \mathrm{C}$ and held at this temperature for $15 \mathrm{~h}$. During the process, a maximum pressure at 320 psi was recorded. After the reaction completed, the reactor was cooled to room temperature. The crude product was transferred to a flask, subjected to a rotary evaporator to remove the un-reacted ethyl acetate. The crude product $(74.0 \mathrm{~g})$ was recovered. The product showed IR absorption of $1650 \mathrm{~cm}^{-1}$ (carbonyl) and $1560 \mathrm{~cm}^{-1}$ (NH) amide, and hydrochloric acid titration basicity of $0.25 \mathrm{mmol} \mathrm{g}^{-1}$ as the indication of low content of starting amines. Similarly, the amide initiators of ED148 diamide, T400 triamide, and DETA triamide were prepared from the amines of ED148, T400, and DETA, accordingly.

\section{Butoxylation of Amide Initiators}

The prepared and commercially available initiator compounds were subjected to a standard condition of butoxylation with 1,2-epoxybutane. An example of amide initiator is described below. The mixture of $\varepsilon$ caprolactam $(17.6 \mathrm{~g}, 0.16 \mathrm{~mol})$ and potassium hydroxide $(0.7 \mathrm{~g}, 0.013 \mathrm{~mol})$ were subjected to a rotary evaporator under a reduced pressure to remove the water by-product, followed by adding 1,2-epoxybutane (BO) 


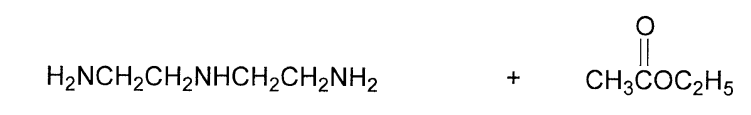

diethylene triamine (DETA)
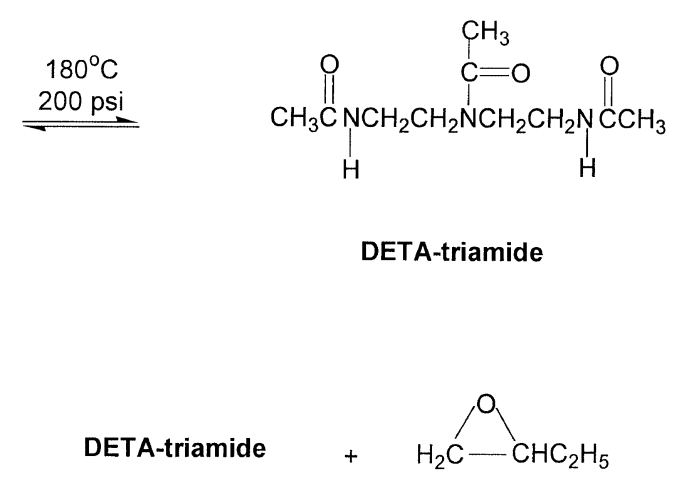

$\mathrm{BO}$

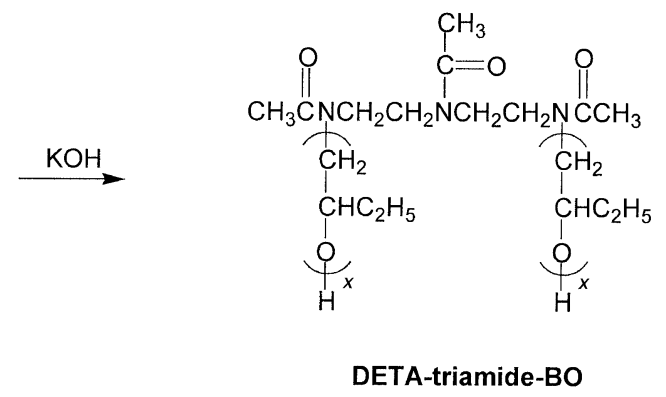

Scheme 1. Preparation of DETA triamide and its butoxylate.

(232.0 g, $3.22 \mathrm{~mol})$ into an autoclave. The autoclave was sealed and purged of air with nitrogen several times. With an initial nitrogen pressure of $200 \mathrm{psi}$, the mixture was heated slowly to $120^{\circ} \mathrm{C}$ and held at this temperature until no more pressure uptake. At room temperature, the excess gas was carefully released and the crude reaction product was transferred to a flask, subjected to a rotary evaporator to remove the unreacted BO and light ends. The crude product $(245.0 \mathrm{~g})$ was recovered in $98 \%$ yield based on the BO added. The product showed IR $1650 \mathrm{~cm}^{-1}$ (amide carbonyl) and $1100 \mathrm{~cm}^{-1}(\mathrm{C}-\mathrm{O}-\mathrm{C})$ absorption. The molecular weight was estimated by using GPC.

The butoxylates of ED148 diamide, DETA triamide and T400 triamide at approximate molecular weights of 1600 were carried out in the similar manner. The preparation of amide initiators and butoxylation is illustrated in Scheme 1.

\section{Characterization}

${ }^{1} \mathrm{H}$ NMR and ${ }^{13} \mathrm{C}$ NMR characterization was carried out by a VARIAN UTITY INOVA FT-NMR $(300 \mathrm{MHz})$ spectrometer using $\mathrm{CDCl}_{3}$ as solvent. FT-IR spectra were obtained using a PERKIN ELMER Paragon 500 FT-IR spectrometer. Gel permeation chromatography (GPC) analyses were performed in the Waters apparatus (515 HPLC pump, 2410 refractive index detector). The Waters Stygel column set was used

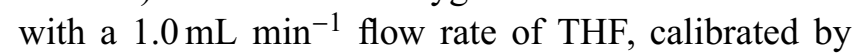
polystyrene standards. Amine titration ${ }^{21}$ was estimated by using ASTM D2073-92 method. Thermal gravimetric analyses (TGA) were performed on a Seiko SII model SSC/5200, by heating the samples from 30 to $500^{\circ} \mathrm{C}$ in air and nitrogen at $10^{\circ} \mathrm{C} \mathrm{m^{-1 }}$. Both types of experiments were carried out under a flow rate of $100 \mathrm{~mL} \mathrm{~min}^{-1}$ and a sample weight of 5-10 mg in Aluminum cells. Each sample had been heating to $100^{\circ} \mathrm{C}$, and hold for $2 \mathrm{~min}$ to remove moisture before subjecting to further heating. Another conditions for isothermal temperature at $250^{\circ} \mathrm{C}$ and $300^{\circ} \mathrm{C}$ were used to simulate the engine burning conditions.

\section{RESULTS AND DISCUSSION}

\section{Synthesis and Structures of Poly(oxybutylene)amides}

The preparation of poly(oxybutylene)amides involving the butoxylation of amide initiators with 1,2epoxybutane was reported previously by our research group. ${ }^{20}$ These poly(oxybutylene)amides have general characteristics with respect to the spectrum of carbonyl absorption at $1650 \mathrm{~cm}^{-1}$ in FT-IR analysis and $174 \mathrm{ppm}(\mathrm{C}=\mathrm{O})$ of ${ }^{13} \mathrm{C}$ NMR for the presence of amide functionalities. A typical reaction is illustrated by using diethylenetriamine (DETA) as a starting material (Scheme 1). The amide was prepared by the amidation of DETA and excess ethyl acetate at high temperature in an autoclave under nitrogen pressure of 200 psi. The formation of DETAtriamide was nearly quantitative under such conditions. It was noticed that the DETA-triamide was water-soluble and hydrophilic in nature. The introduction of oil-solubility was carried out by butoxylation of the amide with 1,2-epoxybutane. The butoxylates of approximately $1600-2000 M_{\mathrm{w}}$ were prepared by using the stoichiometric amount of 1,2-epoxybutane. Data of GPC, polydispersity, amine basicity and FT-IR are listed in Table I. The resulting polymer had three polar amide heads with two long tails of hydrophobic poly(oxybutylene)s. With versatile amide structures, the butoxylated polymers could have different amide arrangements. For example, as shown in Figure 2, a symmetric ED148-diamide-BO and POP230diamide-BO can be drawn as a twin-head-twin-tailed, DETA-triamide-BO as three-head-two-tailed, T400tiamide- $\mathrm{BO}$ as three-head-three-tailed and $\mathrm{Cm}-\mathrm{BO}(\varepsilon-$ caprolactam butoxylates) as a simple one-head-onetailed structure. Since the poly(oxybutylene) segments are considered to be hydrophobic, the amides could exhibit significant hydrophilicity due to the presence 
Table I. Characteristics of poly(oxybutylene)amides ${ }^{\mathrm{a}}$

\begin{tabular}{lcccc}
\hline \multicolumn{1}{c}{ Butoxylates } & $\begin{array}{c}\text { GPC } \\
M_{\mathrm{w}}\end{array}$ & $\begin{array}{c}\text { GPC } \\
\text { Polydispersity }\end{array}$ & $\begin{array}{c}\text { Basicity }_{\mathrm{mmol} \mathrm{g}}{ }^{-1} \\
\text { IR relative intensity }\end{array}$ & $\begin{array}{c}\text { d: } \\
\text { area ratio of } 1650 \mathrm{~cm}^{-1} \\
\text { (amide) to } 1735 \mathrm{~cm}^{-1}(\text { ester })\end{array}$ \\
\hline Cm-BO & 1803 & 1.15 & 0 & 1.00 \\
ED148-diamide-BO & 1623 & 1.08 & 0.15 & 0.05 \\
POP230-diamide-BO & 1683 & 1.12 & 0.20 & 0.44 \\
DETA-triamide-BO & 1435 & 1.09 & 0.20 & 0.06 \\
T400-triamide-BO & 1696 & 1.16 & 0.27 & 0.36 \\
\hline
\end{tabular}

${ }^{\mathrm{a}}$ Reaction conditions: $\mathrm{KOH}, \mathrm{N}_{2} 500 \mathrm{psi}, 120^{\circ} \mathrm{C}$; after $15 \mathrm{~h}$ reaction time for target $1600 \mathrm{M}_{\mathrm{w}}$. ${ }^{\mathrm{b}}$ Based on polystyrene standard and polydispersity $=M_{\mathrm{w}} / M_{\mathrm{n}} \cdot{ }^{\mathrm{c}}$ Total amine basicity estimated by $\mathrm{HCl}$ titration. ${ }^{\mathrm{d}}$ Relative amide/ester ratio analyzed by FT-IR absorption.

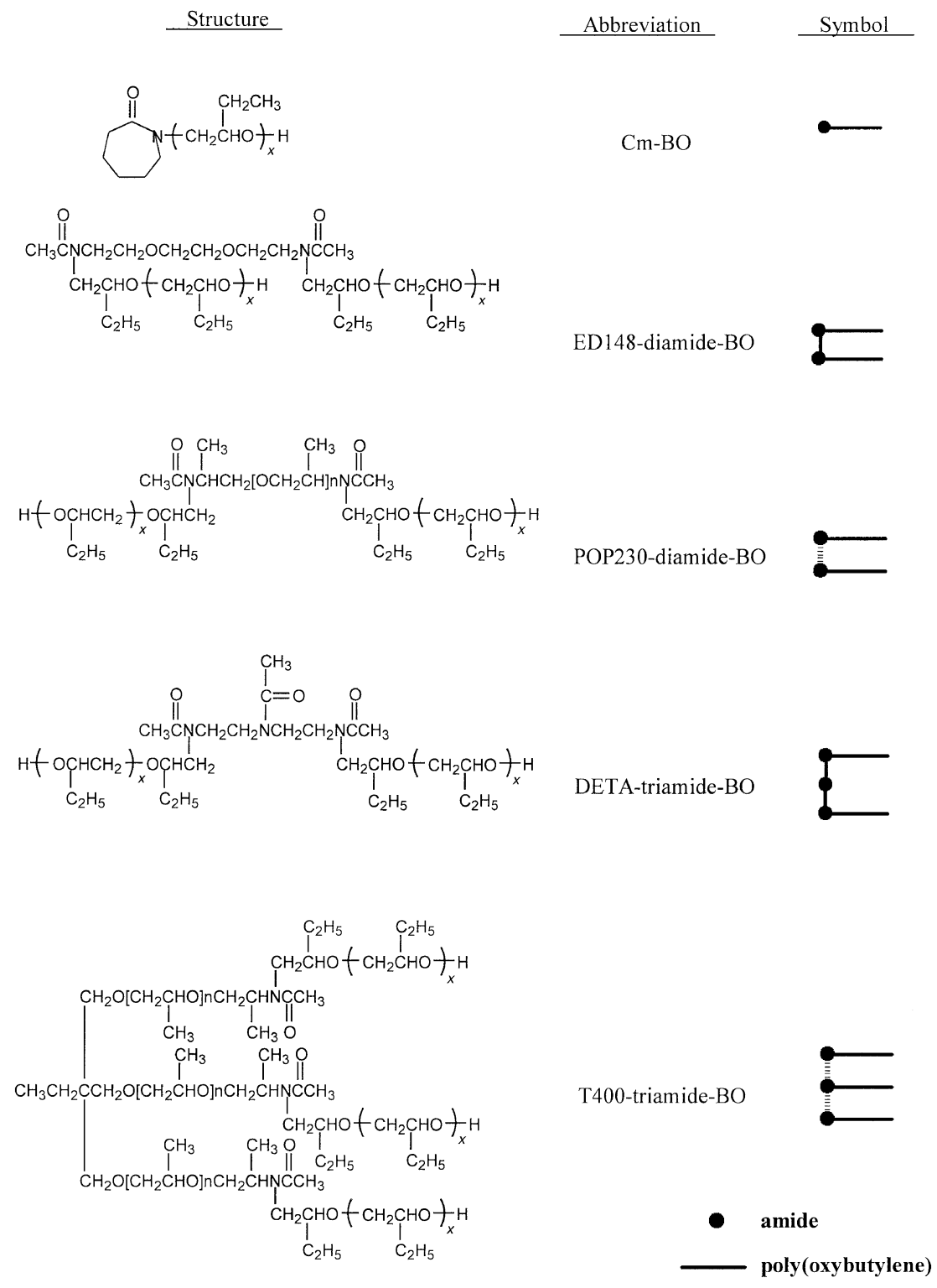

Figure 2. Chemical structures and representation of poly(oxybutylene)amides.

of the polar groups, including the carbonyl, nitrogen lone-paired electrons and possible hydrogen bonds. Their detergency in gasoline has been demonstrated through these structural balances between hydrophobic and hydrophilic natures. As a result, the multiplicity and the arrangement of these amide function- alities in the poly(oxybutylene) backbone extensively affected the detergency performance. ${ }^{13-18}$ For comparison, poly(oxybutylene)-alcohol without amide group was prepared by the butoxylation of $n$-butanol to the same molecular weight, and designated as BuBO1600. The polymer contains no hydrophilic amide but hy- 

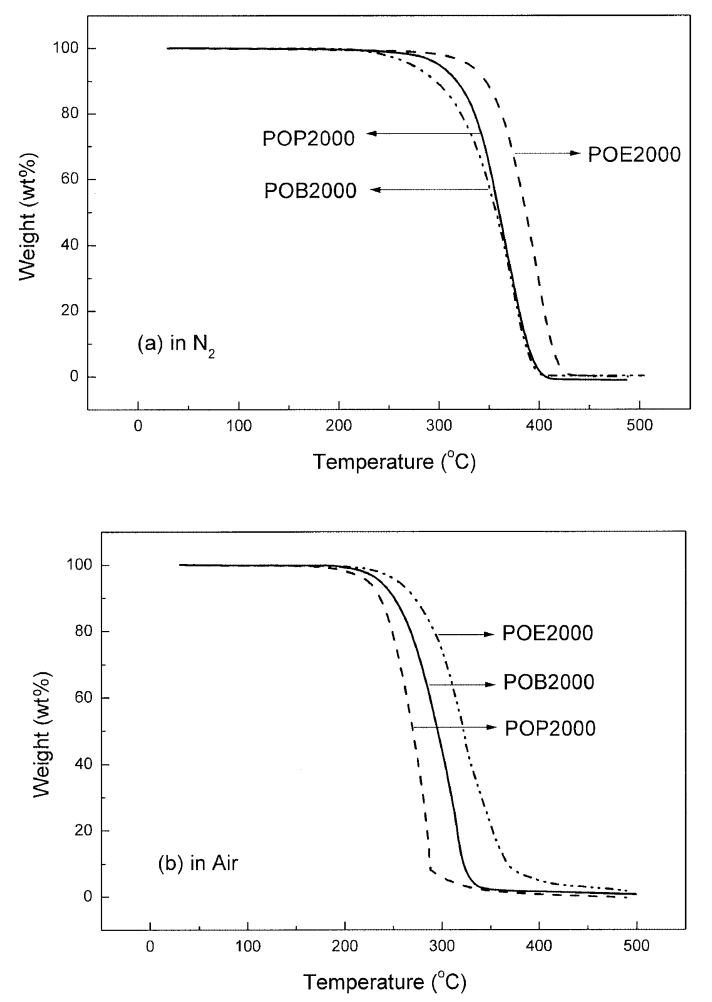

Figure 3. TGA thermograms of poly(oxyalkylene)amines (a) in $\mathrm{N}_{2}$ and (b) in air.

drophobic and oil-soluble. Most of these polymers were investigated as oil-soluble detergents for cleaning intake valve deposits. In addition to the detergency performance, it was believed that those additives could also affect on the reduction of combustion chamber deposits as well as the octane number performance. In other words, the octane number requirements, above the octane number the engine will not knock or the flame-front will not ignite automatically to cause explosive noises, were influenced by the presence of ppm level of additives. However, poly(oxybutylene)amides are found to be positive effect for the combustion behavior, although the mechanism is not been reported in literature.

Relative Stability of POE-, POP-, POB-backboned Amines and Alcohols

The poly(oxyalkylene) backboned amides, amines, alcohols can be structurally classified into polyoxyethylene (POE), polyoxypropylene (POP) and polyoxybutylene (POB) types by the repeating units of $-\left(\mathrm{CH}_{2} \mathrm{CH}_{2} \mathrm{O}\right)-,-\left[\mathrm{CH}_{2} \mathrm{CH}\left(\mathrm{CH}_{3}\right) \mathrm{O}\right]-$ and $-\left[\mathrm{CH}_{2} \mathrm{CH}\left(\mathrm{CH}_{2} \mathrm{CH}_{3}\right) \mathrm{O}\right]-$, respectively. The relative thermal stability of the POE-, POP-, and POB-amines of $2000 M_{\mathrm{w}}$ was investigated by TGA and compared with the corresponding alcohol analogs, PEG2000, PPG2000, and BuBO1600. As shown in Figure 3a, Figure $4 \mathrm{a}$, and Table II, the following thermal stability is observed: POE2000 > POP2000 $\geqq$ POB2000 for
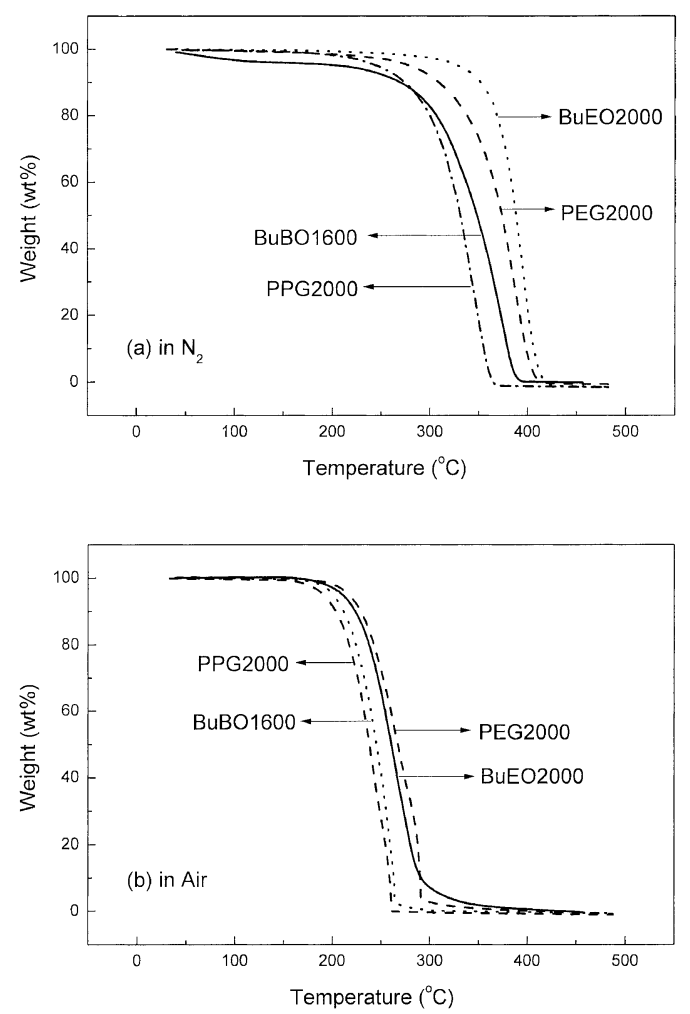

Figure 4. TGA thermograms of poly(oxyalkylene)alcohols (a) in $\mathrm{N}_{2}$ and (b) in air.

Table II. TGA decomposition patterns based on percentages of weight loss in $\mathrm{N}_{2}{ }^{\mathrm{a}}$

\begin{tabular}{lcccc}
\hline \multicolumn{1}{c}{ Materials } & \multicolumn{4}{c}{ Temperature $\left({ }^{\circ} \mathrm{C}\right)$} \\
& $95 \mathrm{wt} \%$ & $75 \mathrm{wt} \%$ & $50 \mathrm{wt} \%$ & $25 \mathrm{wt} \%$ \\
\hline PEG2000 & 279 & 347 & 372 & 389 \\
BuEO2000 & 329 & 374 & 388 & 399 \\
BuBO1600 & 209 & 316 & 348 & 369 \\
PPG2000 & 245 & 307 & 331 & 346 \\
POE2000 & 329 & 367 & 387 & 401 \\
POB2000 & 273 & 329 & 357 & 375 \\
POP2000 & 299 & 341 & 360 & 376 \\
Cm-BO & 278 & 352 & 371 & 384 \\
ED148-diamide-BO & 236 & 312 & 351 & 374 \\
POP230-diamide-BO & 265 & 339 & 359 & 374 \\
DETA-triamide-BO & 299 & 365 & 384 & 397 \\
T400-triamide-BO & 299 & 365 & 384 & 397 \\
\hline${ }^{a}$ Heating rate at $10^{\circ} \mathrm{C}$ min $^{-1}$. & &
\end{tabular}

amines and BuEO2000 > PEG2000 > PPG2000 $\geqq$ BuBO1600 for polyols in nitrogen. Apparently, the POE backbone was more stable than the POP or POB, while the backbones with amine functionality are generally more stable than their alcohol counterparts. For example, with the same backbones, POP2000 or POB2000 $\left(2000 M_{\mathrm{w}}\right)$ was more stable than the corresponding PPG2000, by showing a $50 \mathrm{wt} \%$ retention temperature at about $360^{\circ} \mathrm{C}$ for the former amines and at $330^{\circ} \mathrm{C}$ for the latter (Table II). The differences were attributed to the presence of terminal amines, i.e., $-\mathrm{NH}_{2}$ vs. $-\mathrm{OH}$ in the structures. Moreover, 
Table III. TGA decomposition patterns based on percentages of weight loss in air $^{\mathrm{a}}$

\begin{tabular}{lcccc}
\hline \multicolumn{1}{c}{ Materials } & \multicolumn{4}{c}{ Temperature $\left({ }^{\circ} \mathrm{C}\right)$} \\
& $95 \mathrm{wt} \%$ & $75 \mathrm{wt} \%$ & $50 \mathrm{wt} \%$ & $25 \mathrm{wt} \%$ \\
\hline PEG2000 & 217 & 247 & 267 & 284 \\
BuEO2000 & 210 & 242 & 261 & 276 \\
BuBO1600 & 201 & 229 & 245 & 257 \\
PPG2000 & 191 & 222 & 237 & - \\
POE2000 & 254 & 298 & 322 & 346 \\
POB2000 & 234 & 273 & 295 & 312 \\
POP2000 & 223 & 253 & 269 & 281 \\
Cm-BO & 199 & 236 & 258 & 276 \\
ED148-diamide-BO & 206 & 240 & 261 & 275 \\
POP230-diamide-BO & 219 & 258 & 282 & 304 \\
DETA-triamide-BO & 338 & 291 & 320 & 341 \\
T400-triamide-BO & 252 & 309 & 346 & 367 \\
\hline${ }^{a}$ Heating rate at $10{ }^{\circ} \mathrm{C}$ min $^{-1}$. & &
\end{tabular}

the relative stability in air, shown in Figure $3 \mathrm{~b}$ and $4 \mathrm{~b}$, can be summarized as POE2000 > POB2000 > POP2000 $\geqq$ PEG $2000 \geqq$ BuEO2000 > BuBO1600 $\geqq$ PPG2000. Compared the temperatures of $50 \mathrm{wt} \%$ weight loss, POE 2000 was $55^{\circ} \mathrm{C}$ more stable than that of PEG2000, POB2000 was $50^{\circ} \mathrm{C}$ more than $\mathrm{BuBO} 1600$ and POP2000 amine was $33^{\circ} \mathrm{C}$ higher stability than PPG2000. Additional results are cited in Table III. Again, the backbone structures and the amine groups appeared to be the important factors for the stability. The structural difference between POE, POP, and $\mathrm{POB}$ leads the generation of radicals on primary carbons of $-\left(\mathrm{CH}_{2} \mathrm{CH}_{2} \mathrm{O}\right)_{X}$ - or secondary carbons of $-\left[\mathrm{CH}_{2} \mathrm{CH}\left(\mathrm{CH}_{3}\right) \mathrm{O}\right]_{X^{-}}$and $-\left[\mathrm{CH}_{2} \mathrm{CH}\left(\mathrm{CH}_{2} \mathrm{CH}_{3}\right) \mathrm{O}\right]_{X^{-}}$, respectively. Radicals on the substituted carbons for POP and POB are formed more favorably than on the less substituted carbons for POE. Under the oxidative condition, hydroperoxides are formed more easily on the oxypropylene and oxybutylene than the oxyethylene carbons in rendering low stability for PPG and BuBO1600. ${ }^{22}$ And during the process of generating radicals and undergoing the cleavage chain reactions, the terminal $-\mathrm{NH}_{2}$ could play a radical scavenging effect, particularly in air. ${ }^{23,24}$ However, both of POB2000 amine and POP diamine showed a similar decomposition curve in nitrogen, but POB2000 was $26^{\circ} \mathrm{C}$ more stable than that of POP2000 in air. The difference between the two amines was perhaps due to the amine contents. The amine analyses showed $1.40 \mathrm{mmol} \mathrm{g}^{-1}$ for POB2000 and $1.02 \mathrm{mmol} \mathrm{g}^{-1}$ for POP2000.

\section{Relative Stability of Different Molecule Weights of Poly(oxybutylene)amides}

The various molecular weights of poly(oxybutylene)amides were prepared and compared. The ED148-diamide-BO with molecular weights in the
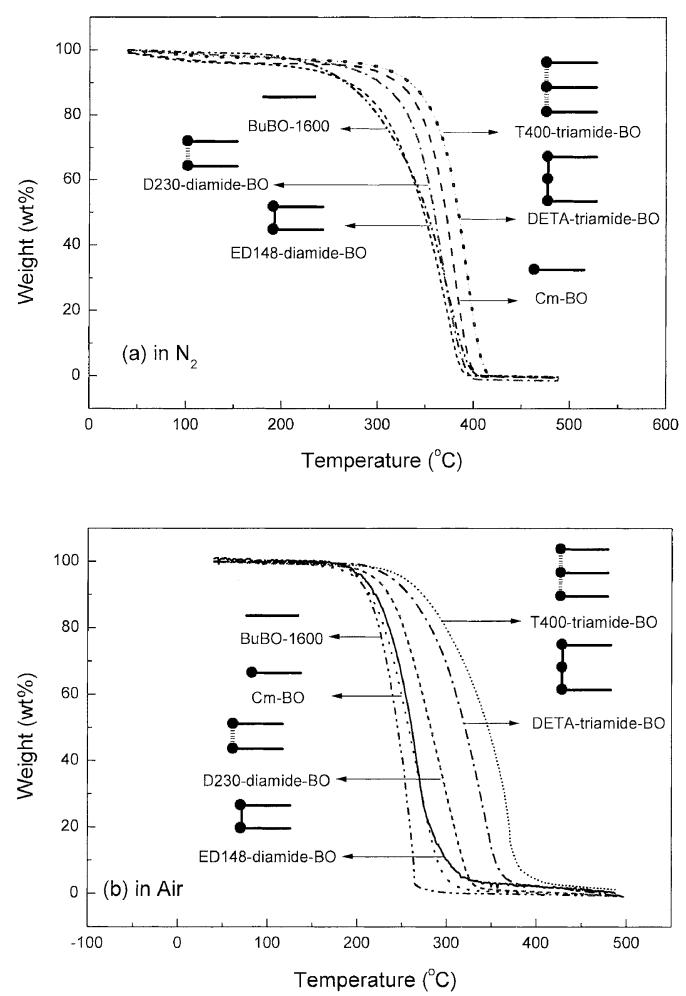

Figure 5. TGA thermograms of poly(oxyalkylene)amides (a) in $\mathrm{N}_{2}$ and (b) in air.

range of 1300-2000 was prepared by controlling the stoichiometric amount of amide initiator and 1,2epoxybutane in the process. Their relative thermooxidative stability was found to be almost identical for GPC molecular weights of 1338, 1623, and 2047, indicating the insignificant difference in molecular weight for thermal stability.

\section{Relative Stability of Four Types of Poly(oxybuty- lene) amides}

The decomposition patterns of amide butoxylates or poly(oxybutylene)amides in nitrogen and in air are shown in Figure 5. The following trend of relative stability is observed: $\mathrm{T} 400$-triamide- $\mathrm{BO}=$ DETA-triamide-BO > POP230-diamide-BO > ED148diamide-BO in nitrogen. The highly stable T400triamide-BO and DETA-triamide-BO were both constituted of three amide functionalities in polymer strains. In comparing their temperatures of $50 \mathrm{wt} \%$ weight loss, the more stable products had a significant difference thermal stability over $20-50^{\circ} \mathrm{C}$ than the diamide butoxylates. On the basis of the structural difference, the amide initiators can be further classified into different classes. Butoxylates derived from the T400triamide initiators have three amides while POP230diamide derivatives have only two amides. The multiple POB backbone structures of T400 derivative displayed higher stability than Gemini type of DETA derivative in air but similar stability in nitrogen. This 


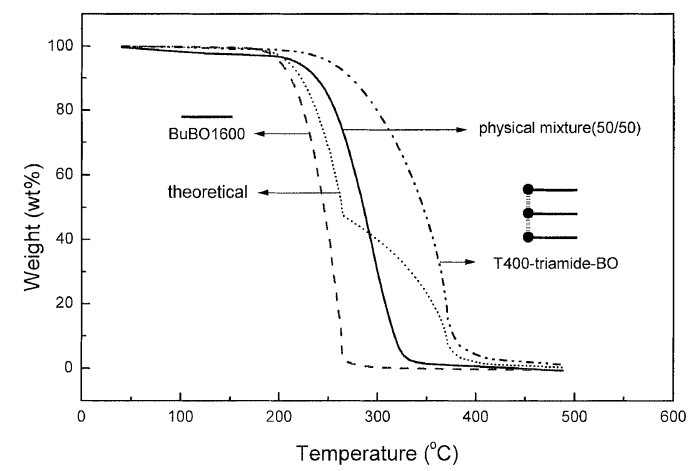

Figure 6. TGA thermograms of T400-triamide derivatives in air.

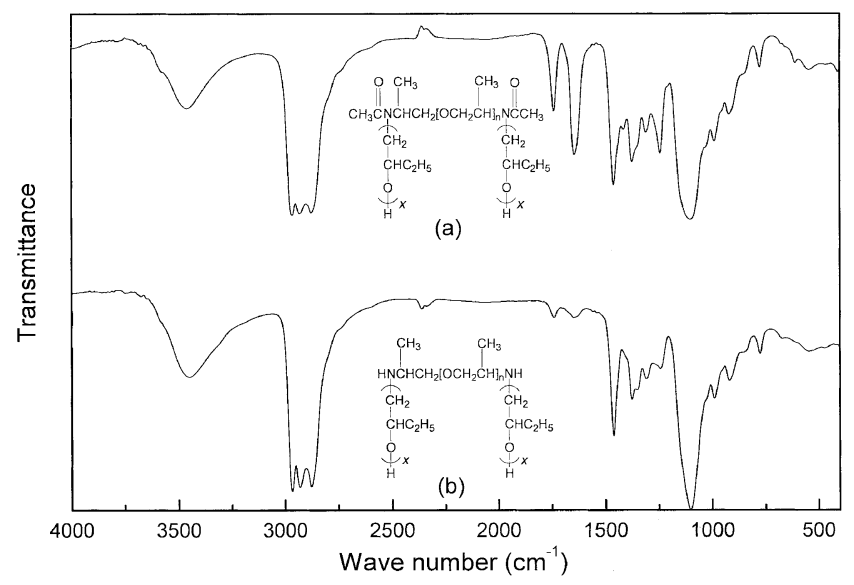

Figure 7. IR spectra of (a) POP230-diamide-BO hydrolysis to (b) POP230-diamine-BO.

indicates that the star-like T400 structure possesses shorter arms of butoxylates in comparing with DETA linear butoxylates, in which the oxidative cleavage of $\mathrm{C}-\mathrm{O}-\mathrm{C}$ bonds may be the predominant parameter in shorting the backbone during degradation. As for the Gemini types of POP230-diamide-BO and ED148diamide-BO, the former was more stable than the latter in both air and nitrogen, although the initiator of ED148 derivative was constituted of more stable POE short middle block. It is reasonably assumed that the labile formation of POP230-amide radical may also play the key contributing factor for stabilization.

The amide effect can be further explained by the theoretical TGA curves of physical mixtures, based on the individual TGA curves of T400-triamide-BO and BuBO1600 at 50/50 weight composition. As shown in Figure 6 , the actual mixing of 50/50 samples of two compounds exhibited a TGA curve with higher stability than the calculated, particularly at the decomposition curve below the $50 \mathrm{wt} \%$ weight loss temperature. This strongly suggested the effectiveness of the built-in amides as antioxidants in the polymer strain in affecting the intermolecular butoxylate, BuBO1600.

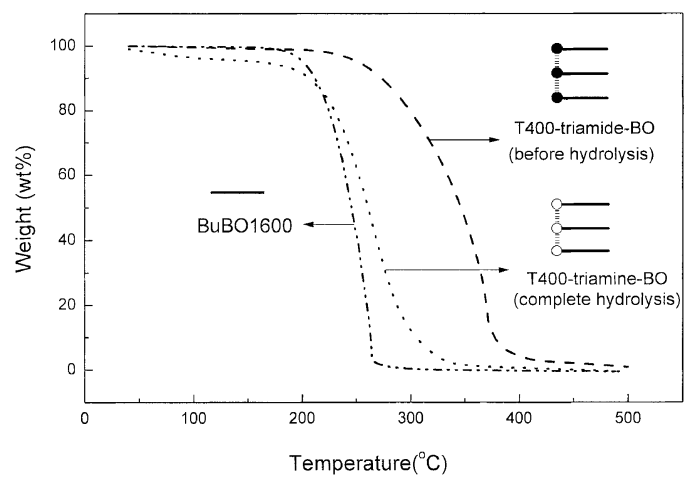

Figure 8. Relative thermoxidative stability of T400-amide, amine, and hydroxy in air.

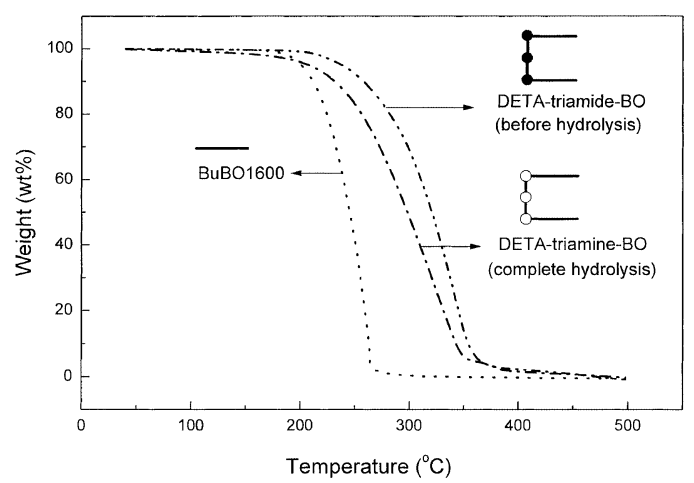

Figure 9. Relative thermoxidative stability of DETA-amide, amine, and hydroxy in air.

Relative Stability of Amide vs. Amine after Hydrolysis

Figure 7 shows the IR spectrum of POP230-diamide$\mathrm{BO}$ products before and after the hydrolysis. The absorption at $1735 \mathrm{~cm}^{-1}$ (ester byproduct) and at $1650 \mathrm{~cm}^{-1}$ (amide main product) of FT-IR analyses indicated the presence of amide butoxylates as the major products and the amide/hydroxy exchanged ester byproducts. ${ }^{20}$ However, both carbonyl absorption peaks disappeared completely in contrast to the remaining $1100 \mathrm{~cm}^{-1}$ ether $(\mathrm{C}-\mathrm{O}-\mathrm{C})$ functionality after the hydrolysis. The result was achieved by subjecting the poly(oxybutylene)amide under the conditions of $20 \mathrm{wt} \%$ hydrochloric acid, refluxing for $10 \mathrm{~h}$. The hydrolysis led to the conversion of amide $(-\mathrm{CONH}-)$ into amine $\left(-\mathrm{NH}_{2}\right)$, evidenced by the basicity titration to be $0.83 \mathrm{mmol} \mathrm{g}^{-1}$. The amide linkage of POP230amide-BO was converted into amine in the hydrolysis process. TGA curves in Figure 8 and 9 showed the relative thermal stability of amide $v s$. amine after hydrolysis compounds. Compared to the amide-rich products, the products after the complete hydrolysis to amines became less stable. However, the hydrolyzed amines were more stable than the alcohol analog, BuBO1600. This confirmed that amide groups were highly effective functionalities for stabilizing the backbones, even more than the amines. Moreover, the hydrolyzed amine of 
Table IV. Comparative stability and char residue(wt $\%$ ) of poly(oxybutylene)amides by TGA

\begin{tabular}{lcccc}
\hline Butoxylates & $90^{\circ} \mathrm{C}^{\mathrm{a}}$ & $250^{\circ} \mathrm{C}^{\mathrm{a}}$ & $250^{\circ} \mathrm{C}^{\mathrm{b}}$ & $300^{\circ} \mathrm{C}^{\mathrm{c}}$ \\
\hline ED148-diamide-BO & 99.3 & 91.8 & 43.1 & 1.5 \\
POP230-diamide-BO & 99.1 & 71.9 & 16.8 & 2.5 \\
DETA-triamide-BO & 99.7 & 96.7 & 76.0 & 21.4 \\
T400-triamide-BO & 98.9 & 93.6 & 80.2 & 29.8 \\
\hline${ }^{\mathrm{a}} \mathrm{Heating}$ rate of & $10^{\circ} \mathrm{C} \mathrm{min}^{-1}$ under & air atmosphere. \\
${ }^{\mathrm{b}}$ Isothermal at $250^{\circ} \mathrm{C}$, hold $30 \mathrm{~min}$ in air. ${ }^{\mathrm{c}}$ Isothermal at \\
$300^{\circ}$, hold 30 min in air.
\end{tabular}

DETA-tiamine-BO was more stable than the analogous T400-triamine-BO. The differences were attributed to the presence of hydrolyzed multiple amines which were backboned by oxyethylene rather than by oxypropylene units, and the stabilizing mechanism can be different between the amides and the amines.

\section{Engine Test and Thermal Stability}

The octane requirement reduction (ORR) tests were used to determine the octane number required for the engine to run without knocking. The ORR of the prepared DETA-triamide-BO (200 ppm in based fuel) was reported to be -0.1 octane number reduction based on the blank fuel in engine test, comparable with a leading brand of commercial product, OGA-480 (0.4). The partially hydrolyzed product significantly improved the octane requirement to 2.1 research otanc number (RON). The positive 2.1 research octane number (RON) means the significant performance difference between the additive and the base fuels. The results also showed that the hydrolyzed poly(oxybutylene)amides to amines adversely affected the octane number requirement performance. It implies the importance of the amide presence for combustion mechanism.

For a high performance engine result, a good gasoline additive should be thermal stable around 250$300^{\circ} \mathrm{C}$ to maintain its detergency at this intake valve temperature. After the detergency performance, the additive was expected to be burn cleanly at $300^{\circ} \mathrm{C}$ in order to leave less residues in the combustion chamber. Table IV shows the comparative stability results by TGA at the required temperature. The data of residual weights (or char residue) at the target temperature would reveal such thermal characteristics. The thermal stability of DETA-triamide-BO and T400-triamide$\mathrm{BO}$ was higher than that of POP230-diamide-BO and ED148-diamide-BO at $250^{\circ} \mathrm{C}$. The high char yield values were contributed to the presence of three amides in the structures. For the target temperature of $300^{\circ} \mathrm{C}$, POP230-diamide-BO and ED148-diamide-BO had low char residues implying the possibly clean burning in the combustion chamber. In this aspect, DETA-triamide$\mathrm{BO}$ and T400-triamide-BO had too high residue and predictably less satisfactory additives.

\section{The Rationales for Relative Stability of Poly(oxybuty- lene) amides}

In general, the thermal stability patterns of poly(oxyalkylene) backboned polymers are different between in air and in nitrogen. In nitrogen, the bond cleavages on $\mathrm{C}-\mathrm{C}$ or $\mathrm{C}-\mathrm{O}$ of poly(oxyalkylene) backbone via homolytic carbon radicals. However, in the presence of oxygen, the formation of peroxide is believed to be the predominant route leading to the degradation. As illustrated in Scheme 2, the initiation or the $\mathrm{C}-\mathrm{O}$ scission intermediates are shown to be the route to the decomposition. In the presence of amide groups, the amido radicals are possibly generated to be the lowest energy level of radical species, which can stabilize or intercept the consequent decomposition route. The amido radical is considered to be the more effective scavenger than the amino radical. And amide radical may be generated by the $\mathrm{N}-\mathrm{C}$ cleavage while the amine radical can be formed mainly by $\mathrm{N}-\mathrm{H}$ cleavage. Under this assumption, the poly(oxybutylene)triamides are significantly more stable than the diamide and monoamide due to its abundance of antioxidant species. Because of the built-in amide functionalities in the polymer strains, the polymer stability is greatly enhanced. However, the detailed mechanism for amide radical forming and the interaction with the BO backbone is not completely understood.

\section{CONCLUSIONS}

A family of poly(oxybutylene)amides were prepared by a two-step synthesis involving the formation of various amides and the consequent butoxylation with 1,2-epoxybutane. The thermal stability of these poly(oxybutylene)amides was mainly contributed by the presence of multiple amide groups which acted as built-in antioxidants. In comparing the decomposition pattern of the simple BuBO1600 structure without amide functionality, the difference in stability up to $100^{\circ} \mathrm{C}$ for the $50 \mathrm{wt} \%$ weight loss temperatures had been observed for DETA-triamide-BO and T400triamide-BO in TGA. For the gasoline additive applications, the combustion in automobile engine required the molecules stable around $250^{\circ} \mathrm{C}$ but cleanly decomposed at high temperature of $300^{\circ} \mathrm{C}$ without leaving residues. The understanding of thermal stability in molecular level is found to be the important factor for designing a viable commercial gasoline additive.

Acknowledgments. We thank National Science Council (NSC) and Chinese Petroleum Corp. (Taiwan) 


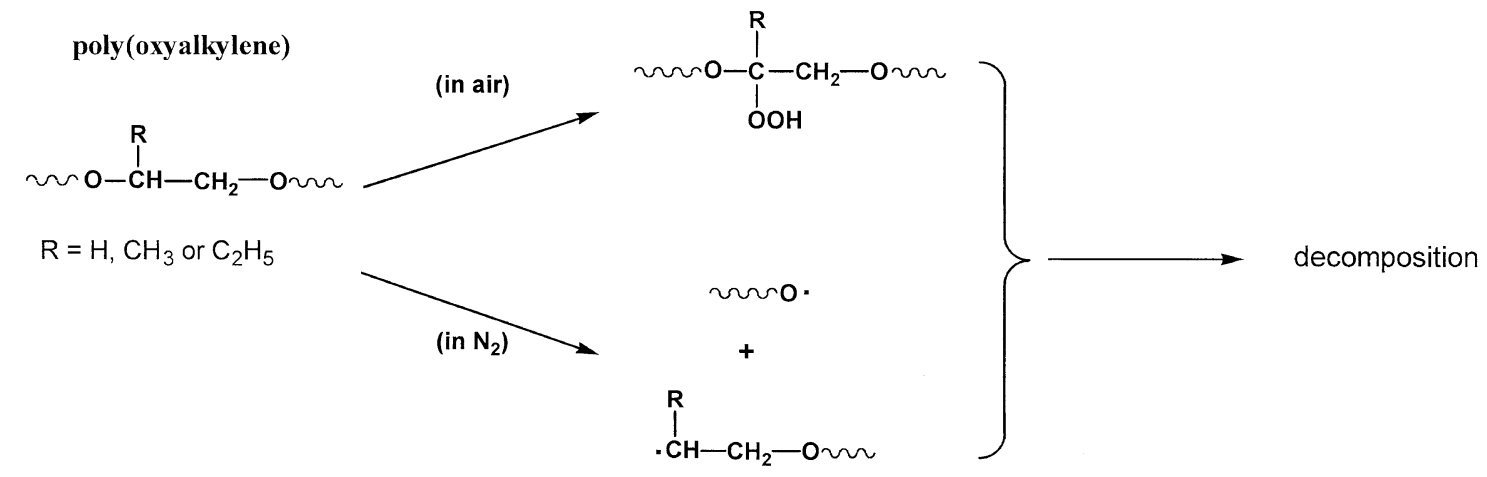

poly(oxyalkylene)amide

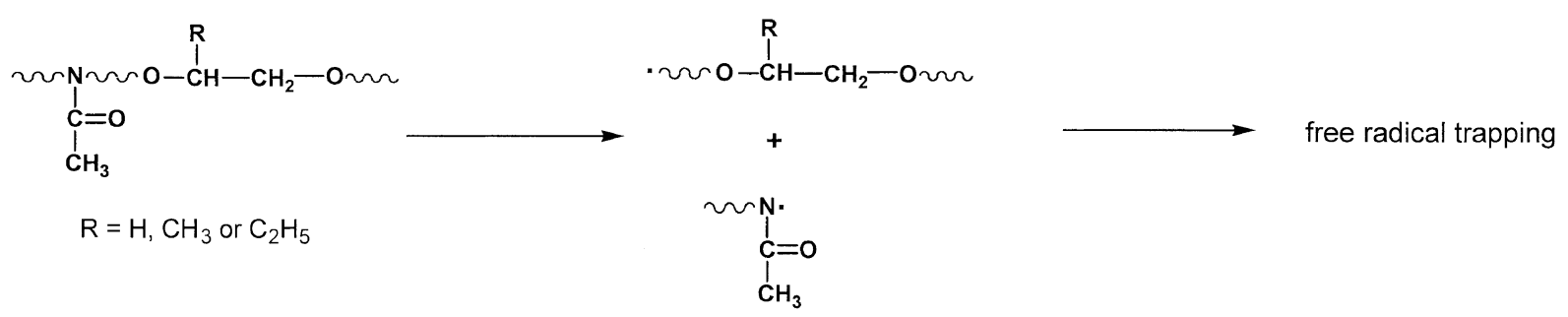

Scheme 2. Free radical breaking of poly(oxyalkylene) backbones and stabilized by amines.

for their financial supports and technical assistance for performing the engine tests.

\section{REFERENCES}

1. K. Owen and R. G. M. Landells, Ed., "Gasoline and Diesel Fuel Additives”, John Wiley \& Sons Ltd., Chichester, 1989.

2. S. Herbsman and K. Virk, Chemtech, 242 (1990).

3. J. H. Udelhofen and T. J. Zahalka, Ed., "Gasoline Additive Requirements for Today's Smaller Engines”, SAE 881644, 1988.

4. M. T. Gillies, in "Chemical Additives for Fuels; Developments Since 1978”, Noyes Data Corp., Park Ridge, NJ, 1982.

5. L. D. Burns, Chemtech, 744 (1984).

6. R. P. Aiello, M. J. Riley, and H. D. Millay, U. S. Patent 5006 130 (Apr. 9, 1991).

7. D. Jamois, M. Tessier, and E. Marechal, J. Polym. Sci., Part A: Polym. Chem., 31, 1923 (1993).

8. R. A. Lewis and L. R. Honnon, U. S. Patent 4236020 (Nov. $25,1980)$.

9. J. E. Lilburn, U. S. Patent 4197409 (Apr. 8, 1980).

10. R. E. Cherpeck, U. S. Patent 5192335 (Mar. 9, 1993).

11. R. A. Lewis and L. R. Honnon, U. S. Patent 4191537 (Mar. 1, 1980).

12. L. D. Sung, U. S. Patent 4981493 (Jan. 1, 1991).

13. J. J. Lin, J. R. Macias, E. J. Haury, S. L. Weaver, C. L. Edward,
P. C. Wang, and G. G. Vaporciyan, U. S. Patent 5352251 (Oct. 4, 1994).

14. J. J. Lin, P. C. Wang, and S. L. Weaver, U. S. Patent 5458660 (Oct. 17, 1995).

15. J. J. Lin and S. L. Weaver, U. S. Patent 5458661 (Oct. 17, 1995).

16. J. J. Lin, P. C. Wang, and S. L. Weaver, U. S. Patent 5489315 (Feb. 6, 1996).

17. J. J. Lin and S. L. Weaver, U. S. Patent 5492546 (Feb. 20, 1996).

18. J. J. Lin, P. C. Wang, and S. L. Weaver, U. S. Patent 5507843 (Apr. 16, 1996).

19. V. M. Nace, Ed., "Nonionic Surfactants-Polyoxyalkylene Block Copolymers", Marcel Dekker, Inc., New York, N.Y., 1996.

20. J. J. Lin, J. J. Wu, and Y. S. Ho, J. Appl. Polym. Sci. ,82, 435 (2001).

21. J. J. Lin, S. F. Lin, T. T. Kuo, F. C. Chang, and F. P. Tseng, J. Appl. Polym. Sci., 78, 615 (2000).

22. G. K. Hoeschele, Angew. Makromol. Chem., 58/59, 299 (1997).

23. T. Zaharescu, S. Jipa, R. Setnescu, D. Wurm, M. J. S. Brites, M. A. F. Esteves, M. J. Marcelo-Curto, and B. Gigante, Polym. Degrad. Stab., 68, 83 (2000).

24. J. J. Lin, S. M. Shau, and K. M. Wei, Polym. Degrad. Stab., 70, 171 (2001). 